\title{
Efeito do AIB no enraizamento de estacas herbáceas do porta- enxerto de videira VR 43-43 em diferentes substratos
}

\section{Effect of IBA on the rotting of herbaceous cuttings of VR 43-43 grapevine rootstoks in different substrates}

\author{
Alessandro Borini Lone ${ }^{*}$; Ernesto Lema López ${ }^{2}$; \\ Sara Regina Silvestrin Rovaris ${ }^{3}$; Daniela Fernanda Klesener ${ }^{4}$; \\ Leandro Higashibara ${ }^{5}$; Letícia Trindade Ataíde ${ }^{6}$; Sérgio Ruffo Roberto ${ }^{7}$
}

\begin{abstract}
Resumo
O presente trabalho teve por objetivo avaliar o enraizamento de estacas herbáceas do porta-enxerto de videira VR 43-43 em três concentrações de AIB (0, 1000 e 2000 mg. $\left.\mathrm{L}^{-1}\right)$ e dois substratos (vermiculita e casca de arroz carbonizada). O delineamento foi o inteiramente casualizado, em arranjo fatorial $2 \times 3$ com cinco repetições e 10 estacas por parcela. As variáveis avaliadas foram: porcentagem de retenção foliar, porcentagem de estacas enraizadas; número de raízes por estaca; comprimento de raízes $(\mathrm{cm})$; porcentagem brotação, porcentagem de estacas vivas; massa de matéria seca e fresca das raízes por estaca (g). Houve influência do substrato apenas na massa fresca e seca das raízes, com as maiores médias observadas para a casca de arroz carbonizada. Para as doses aplicadas de AIB, foi verificada maior porcentagem de sobrevivência e porcentagem de estacas enraizadas no grupo controle (sem aplicação de AIB) e com aplicação de $1.000 \mathrm{mg} \cdot \mathrm{L}^{-1}$. Não houve diferença significativa na interação entre substrato e aplicação de AIB. Conclui-se que a casca de arroz carbonizada é indicada para o enraizamento de estacas herbáceas do porta-enxerto VR 43-43, não sendo necessária a aplicação de AIB.
\end{abstract}

Palavras-chave: Auxina, casca de arroz carbonizada, vermiculita, Vitis vinifera

\begin{abstract}
The present work had the aim of evaluating the rooting of herbaceous cuttings of VR 43-43 grapevine rootstocks with three IBA concentrations $\left(0 ; 1,000\right.$ and 2,000 mg. $\left.\mathrm{L}^{-1}\right)$ and two substrates (vermiculite and carbonized rice husk). A randomized design was used in a $2 \times 3$ factorial arrangement with five replications and 10 cuttings per plot. The appraised variables were: percentage of leaf retention, percentage
\end{abstract}

\footnotetext{
${ }^{1}$ Biólogo, Mestre em Fitotecnia pelo Departamento de Agronomia da Universidade Estadual de Londrina, Caixa Postal 6001, 86051-990, Londrina, PR. E-mail: alone_bio@yahoo.com.br

${ }^{2}$ Engenheiro Agrônomo, Mestre em Fitosanidade pelo Departamento de Agronomia da Universidade Estadual de Londrina, Caixa Postal 6001, 86051-990, Londrina, PR. E-mail: lema.ernesto@gmail.com

${ }^{3}$ Engenheira Agrônoma, Mestre em Melhoramento Vegetal pelo Departamento de Agronomia da Universidade Estadual de Londrina, Caixa Postal 6001, 86051-990, Londrina, PR. E-mail sara_rsr@yahoo.com.br

${ }^{4}$ Bióloga, Mestre em Entomologia pelo Departamento de Agronomia da Universidade Estadual de Londrina, Caixa Postal 6001, 86051-990, Londrina, PR. E-mail: daniela.klesener@gmail.com

${ }^{5}$ Engenheiro Agrônomo, Mestre em Tecnologia de Aplicação de Agrotóxicos pela Universidade Estadual de Londrina, Caixa Postal 6001, 86051-990, Londrina, PR. E-mail:riyuitih@hotmail.com

${ }^{6}$ Engenheira Agrônoma, Doutoranda em Agronomia no Departamento de Agronomia da Universidade Estadual de Londrina, Caixa Postal 6001, 86051-990, Londrina, PR. E-mail: leticia_trindade@yahoo.com.br

${ }^{7}$ Professor, Doutor do Departamento de Agronomia da Universidade Estadual de Londrina, Caixa Postal 6001, CEP 86051-990, Londrina, PR. E-mail: sroberto@uel.br

* Autor para correspondência
} 
of rooted cuttings; number of roots; length of roots $(\mathrm{cm})$; percentage of sprouting, percentage of alive cuttings; mass of dry and fresh matter of the roots for each cutting (g). There was only influence of the substrate in the fresh and dry mass of the roots, with the largest averages observed for the carbonized rice husk. For the IBA doses, it was verified the highest survival percentage and percentage of rooted cuttings in the control group (without IBA application) and with IBA at 1,000 mg.L. $\mathrm{L}^{-1}$. There were no significant differences for the interaction between substrate and IBA application. Carbonized rice husk is suitable for the rooting of herbaceous cuttings of VR 43-43 rootstocks, not being necessary the IBA application.

Key words: Auxin, carbonized rice husk, vermiculite, Vitis vinifera

\section{Introdução}

O método mais usado de propagação de mudas na viticultura mundial para a formação de pomares é o assexuado, através do emprego da estaquia de porta-enxertos e posterior enxertia da cultivar a ser cultivada (SOUSA, 1996).

O porta-enxerto de videira 'VR043-43' é um híbrido proveniente do cruzamento de Vitis vinifera e Vitis rotundifolia, apresentando elevada resistência ao Fusarium oxysporum f. sp. herbemontis e à filoxera, alta tolerância à pérola-da-terra e uma quase imunidade a alguns nematóides (ANDRADE; DAL BÓ; SCHUCK, 1994; SCHUCK, 2003), no entanto as estacas das cultivares da seção Muscadínea (Vitis rotundifolia), da família Vitaceae, assim como seus híbridos, apresentam baixo índice de enraizamento, possivelmente devido à presença de inibidores ou ausência de substâncias promotoras, o que torna sua utilização limitada (PIRES; BIASI, 2003).

Dentreassubstâncias promotoras deenraizamento destacam-se as auxinas, sendo o ácido indolbutírico (AIB), a principal auxina sintética de uso geral, porque não é tóxica para a maioria das plantas, mesmo em altas concentrações; é bastante efetiva para um grande número de espécies e relativamente estável, sendo pouco suscetível à ação dos sistemas de enzimas de degradação de auxinas (PIRES; BIASI, 2003).

O processo de formação de raízes em estacas pode ser limitado também pelo substrato utilizado (FACHINELLO et al., 1995), que influi na qualidade das raízes formadas e no percentual de enraizamento. Dentre os materiais comumente utilizados para enraizamento estão a vermiculita e a casca de arroz carbonizada. Devido à elevada porosidade e boa retenção de umidade, a vermiculita é cada vez mais utilizada como substrato para enraizamento de estacas herbáceas e semi-lenhosas (GONÇALVES; MINAMI, 1994; FACHINELLO et al., 1995). A casca de arroz carbonizada é um substrato que possui elevado volume de espaço de aeração e resistência à decomposição, sem riscos de falta de oxigênio para as raízes (BELLÉ, 1990), baixa densidade e alta permeabilidade à água, conferindo ao substrato, ao qual for misturada, maior aeração e drenagem (BACKES, 1990). A casca de arroz carbonizada já é recomendada como substrato para enraizamento de estacas herbáceas dos porta-enxertos de videira Campinas (IAC 766) e Jales (IAC 572) (ROBERTO et al., 2004), e juntamente com a vermiculita, para o enraizamento de goiabeira (cultivares paluma e século XXI) (ZIETEMANN; ROBERTO, 2007) e aceroleira 'Dominga' (Malpighia emarginata D.C.) (ROBERTO; PAIOLO, 2002).

O objetivo do trabalho foi avaliar o efeito de diferentes concentrações de AIB no enraizamento de estacas herbáceas do porta-enxerto de videira VR 43-43 em vermiculita e casca de arroz carbonizada.

\section{Material e Métodos}

O estudo foi realizado em casa de vegetação na Universidade Estadual de Londrina (UEL), Paraná, localizada a $23^{\circ} 23^{\prime} \mathrm{S}$ e $51^{\circ} 11^{\prime} \mathrm{W}$ e altitude média de $560 \mathrm{~m}$, durante o período de 11 de março a 16 de abril de 2008. Segundo a classificação de Köppen, o clima da região é do tipo Cfa (subtropical úmido). 
Foram utilizadas estacas herbáceas de $15 \mathrm{~cm}$ da parte mediana dos ramos do porta-enxerto de videira VR 43-43 pertencente a Fazenda Escola da UEL.

O preparo das estacas consistiu em um corte horizontal logo abaixo de um nó com a eliminação das folhas da parte basal, deixando-se apenas uma folha (ou nó) na parte superior. Durante o preparo das estacas, estas foram dispostas provisoriamente em um recipiente com água para evitar a desidratação. Após o seu preparo, as estacas foram submetidas à aplicação de duas concentrações de AIB (1.000 e $2.000 \mathrm{mg} . \mathrm{L}^{-1}$ ) mais controle (só água) através de imersão rápida (5 segundos) da sua porção basal.

Em seguida, as estacas foram imediatamente colocadas em orifícios eqüidistantes em caixas plásticas $(44 \times 30 \times 7 \mathrm{~cm})$ contendo dois tipos de substrato (casca de arroz carbonizada e vermiculita grânulos médios). As estacas foram irrigadas por câmara de nebulização com regime intermitente controlado por temporizador e válvula solenóide. A válvula foi programada para nebulizar as estacas durante 10 segundos a intervalos de 3 minutos durante todo o experimento. O bico nebulizador empregado (Modelo Mist DanSprinklers, Israel) apresenta vazão de 35 L.hora $^{-1}$. A câmara de nebulização encontra-se inserida em uma estufa agrícola com cobertura de filme de polietileno transparente e sombrite $30 \%$.

O delineamento experimental foi o inteiramente casualizado, em arranjo fatorial $2 \times 3$ (2 tipos de substratos e 3 doses de AIB) com 5 repetições, sendo que cada parcela foi composta por 10 estacas. Para o controle de doenças fúngicas, as estacas foram tratadas semanalmente com fungicidas sistêmicos (benomyl a 1\%) por pulverização.

Os parâmetros avaliados foram: porcentagem de retenção foliar, porcentagem de estacas enraizadas; número de raízes por estaca; comprimento médio das raízes $(\mathrm{cm})$; porcentagem brotação, porcentagem de estacas vivas; massa de matéria seca e fresca das raízes por estaca (g). A matéria seca das raízes foi obtida pela secagem em estufa com temperatura de $65^{\circ} \mathrm{C}$ por $48 \mathrm{~h}$ (MACHADO et al., 2005) e o comprimento médio das raízes foi obtido pela somatória do comprimento $(\mathrm{cm})$ de cada raiz dividido pelo número de raízes por estaca.

Os dados obtidos foram submetidos a análise de variância, e a comparação das médias foi realizada pelo teste de Tukey a 5\% de probabilidade.

\section{Resultados e Discussão}

Os resultados mostraram que só houve influência do substrato na massa fresca e seca das raízes, com as maiores médias observadas para a casca de arroz carbonizada (Tabela 1 e 2). Resultado semelhante foi obtido por Roberto et al. (2004), em seu trabalho com enraizamento de estacas de porta-enxerto de videira IAC 766 e IAC 572. Segundo esses autores o maior desenvolvimento radicular observado no substrato casca de arroz carbonizada deve-se, provavelmente, à melhor oxigenação e drenagem que este substrato confere. Além disso, este substrato apresenta outras características favoráveis ao enraizamento de estacas, como baixo peso e boa porosidade (PIRES; BIASI, 2003).

Para as doses aplicadas de AIB, foi verificada maior porcentagem de sobrevivência no grupo controle (sem aplicação de AIB) e com aplicação de $1.000 \mathrm{mg} . \mathrm{L}^{-1}$ (Tabela 2). A menor porcentagem de sobrevivência das estacas tratadas com a concentração de $2.000 \mathrm{mg} . \mathrm{L}^{-1}$ pode ser explicado pelo efeito tóxico da dose de AIB. Esse efeito também foi verificado por outros autores em trabalhos com porta-enxertos de videira (SILVA; FACHINELLO. MACHADO, 1986; LEONEL; RODRIGUES, 1993; BIASI; POMMER; PINO, 1997; BIASI; BOSZCZOWSKI, 2005). Outros fatores que também podem influenciar na sobrevivência das estacas é a permanência prolongada na câmara de nebulização e o excesso de umidade (HARTMANN et al., 1997). 
Tabela 1. Porcentagem de retenção foliar, estacas enraizadas, sobrevivência e brotação de estacas do porta-enxerto de videira VR 43-43 em diferentes concentrações de AIB e substratos. Londrina, PR, 2008.

\begin{tabular}{|c|c|c|c|c|c|}
\hline Tratamentos & & $\begin{array}{c}\text { Retenção } \\
\text { foliar }\end{array}$ & $\begin{array}{c}\text { Estacas } \\
\text { enraizadas }\end{array}$ & Sobrevivência & Brotação \\
\hline \multicolumn{6}{|l|}{ Substrato } \\
\hline Casca de arroz carbonizada & & $4,0 \mathrm{a}$ & $35,3 \mathrm{a}$ & $55,3 \mathrm{a}$ & $19,5 \mathrm{a}$ \\
\hline Vermiliculita & & $1,3 \mathrm{a}$ & $30,7 \mathrm{a}$ & $42,7 \mathrm{a}$ & $17,3 \mathrm{a}$ \\
\hline \multicolumn{6}{|l|}{$\operatorname{AIB}\left(m g . L^{-1}\right)$} \\
\hline 0 & & $1,0 \mathrm{a}$ & $41,0 \mathrm{a}$ & $66,0 \mathrm{a}$ & $42,0 \mathrm{a}$ \\
\hline 1.000 & & $4,0 \mathrm{a}$ & $39,0 \mathrm{a}$ & $56,0 \mathrm{a}$ & $6,2 \mathrm{~b}$ \\
\hline 2.000 & & $3,0 \mathrm{a}$ & $19,0 \mathrm{~b}$ & $25,0 \mathrm{~b}$ & $7,0 \mathrm{~b}$ \\
\hline Causas de Variação & GL & & $\mathrm{F}$ & & \\
\hline Substrato & 1 & $2,7 \mathrm{~ns}$ & $0,5 \mathrm{~ns}$ & $2,0 \mathrm{~ns}$ & $0,1 \mathrm{~ns}$ \\
\hline AIB & 2 & $1,2 \mathrm{~ns}$ & $4,1 *$ & $6,4 *$ & $8,7 *$ \\
\hline Substrato*AIB & 5 & $0,2 \mathrm{~ns}$ & $0,1 \mathrm{~ns}$ & $1,2 \mathrm{~ns}$ & $0,4 \mathrm{~ns}$ \\
\hline Resíduo & 24 & - & - & - & - \\
\hline
\end{tabular}

Médias seguidas da mesma letra na coluna não diferem estatisticamente pelo teste de Tukey a 5\% de probabilidade.

“*” e "ns" indicam diferenças significativas e não significativas, respectivamente, ao 5\% pelo teste $\mathrm{F}$.

Tabela 2. Número de raízes por estaca, comprimento médio das raízes ( $\mathrm{cm}$ ), massa fresca (MF) e seca (MS) das raízes por estaca (g) do porta-enxerto de videira VR 43-43 em diferentes concentrações de AIB e substratos. Londrina, PR, 2008.

\begin{tabular}{|c|c|c|c|c|c|}
\hline Tratamentos & & Raízes/estaca & $\begin{array}{c}\text { Comprimento } \\
\text { de raízes }\end{array}$ & $\begin{array}{c}\text { MF raiz/ } \\
\text { estaca }\end{array}$ & $\begin{array}{c}\text { MS raiz/ } \\
\text { estaca }\end{array}$ \\
\hline \multicolumn{6}{|l|}{ Substrato } \\
\hline Casca de arroz carbonizada & & $4,3 \mathrm{a}$ & $19,8 \mathrm{a}$ & $0,434 \mathrm{a}$ & $0,030 \mathrm{a}$ \\
\hline Vermiliculita & & $3,2 \mathrm{a}$ & $9,6 \mathrm{a}$ & $0,164 \mathrm{~b}$ & $0,012 \mathrm{~b}$ \\
\hline \multicolumn{6}{|l|}{$\operatorname{AIB}\left(\mathrm{mg} \cdot \mathrm{L}^{-1}\right)$} \\
\hline 0 & & $2,5 \mathrm{a}$ & $10,0 \mathrm{a}$ & $0,244 \mathrm{a}$ & $0,016 \mathrm{a}$ \\
\hline 1.000 & & $4,6 \mathrm{a}$ & $18,6 \mathrm{a}$ & $0,351 \mathrm{a}$ & $0,027 \mathrm{a}$ \\
\hline 2.000 & & $4,0 \mathrm{a}$ & $15,4 \mathrm{a}$ & $0,304 \mathrm{a}$ & $0,020 \mathrm{a}$ \\
\hline Causas de Variação & GL & & $\mathrm{F}$ & & \\
\hline Substrato & 1 & $0,9 \mathrm{~ns}$ & $3,4 \mathrm{~ns}$ & $9,2 *$ & $7,6 *$ \\
\hline AIB & 2 & $1,2 \mathrm{~ns}$ & $0,8 \mathrm{~ns}$ & $0,5 \mathrm{~ns}$ & $0,9 \mathrm{~ns}$ \\
\hline Substrato*AIB & 5 & $0,6 \mathrm{~ns}$ & $0,4 \mathrm{~ns}$ & $0,3 \mathrm{~ns}$ & $0,6 \mathrm{~ns}$ \\
\hline Resíduo & 24 & - & - & - & - \\
\hline
\end{tabular}

Médias seguidas da mesma letra na coluna não diferem estatisticamente pelo teste de Tukey a 5\% de probabilidade.

“*” e "ns" indicam diferenças significativas e não significativas, respectivamente, ao 5\% pelo teste F.

Em relação à porcentagem de estacas enraizadas, as maiores médias também foram obtidas no grupo controle e com aplicação de $1.000 \mathrm{mg} . \mathrm{L}^{-1}$ de AIB, sendo estatisticamente maiores ao enraizamento com aplicações de AIB na concentração de 2.000 mg.L -1 $^{-1}$ Tabela 2). Segundo Ramos et al.
(2003), o fornecimento exógeno de auxina, em certas quantidades, pode promover uma alteração hormonal, favorecendo ou não o enraizamento de estacas. Fachinello et al. (1994), citado por Ferreira, Kersten e Fachinello (2002), indica que um aumento da concentração de auxina exógena 
aplicada em estacas provoca efeito estimulador de raízes até um valor máximo, a partir do qual qualquer acréscimo de auxinas tem efeito inibitório. A mesma tendência foi obtida por Biasi, Pommer e Pino (1997), os quais trabalhando com distintos porta-enxertos semilenhosos de videira, obtiveram um enraizamento máximo com $1.000 \mathrm{mg} . \mathrm{L}^{-1}$ de AIB, e valores menores com concentrações de 0 e 2.000 mg. $L^{-1}$. Machado et al. (2005), obtiveram uma diminuição do enraizamento do porta-enxerto VR 043-43 ao tratarem as estacas com concentrações crescentes de AIB, mas a diferença do presente ensaio, eles obtiveram uma porcentagem máxima de $92,5 \%$ de enraizamento no controle.

A maior porcentagem de brotação foi obtida no grupo controle (42\%) (Tabela 2), resultado que está de acordo com Botelho et al. (2005), que verificaram em seu trabalho, alta porcentagem de brotação $(84,0 \%)$ de estacas herbáceas de portaenxerto de videira VR 43-43 (Vitis vinifera $\mathrm{x}$ Vitis rotundifolia) não tratadas com reguladores vegetais. $\mathrm{O}$ mesmo resultado utilizando o mesmo porta-enxerto foi obtido por Machado et al. (2005), que observaram uma porcentagem de brotação de 31,2 \% no controle e uma diminuição em relação ao aumento da concentração de AIB. Os mesmos autores propõem que isso pode ter ocorrido devido a uma maior porcentagem de estacas enraizadas na ausência de AIB. Biasi, Pommer e Pino (1997), também encontraram uma maior porcentagem de brotação com o grupo controle (45,8 \%), mas não obtiveram diferenças significativas entre todas as concentrações utilizadas $(0,500,1.000,2.000$ mg. $\left.L^{-1}\right)$.

De acordo com Jarvis (1986), a aplicação exógena de auxina depende da idade do ramo de onde as estacas foram coletadas, do tempo entre a coleta do material e o tratamento, da concentração, do tipo de auxina sintética usada e da duração do tratamento.
Para as demais variáveis avaliadas não houve diferença significativa, mostrando não ter ocorrido influência das doses utilizadas para essas variáveis (Tabela 1 e 2).

A análise dos dados também mostrou que não houve diferença significativa na interação entre substrato e aplicação de AIB (Tabela 1 e 2).

\section{Conclusões}

Com uso do substrato casca de arroz carbonizada se obteve um maior peso de raízes por estacas herbáceas do porta-enxerto de videira VR 043-43 em comparação ao substrato vermiculita de grânulo médio.

Em relação à adição de AIB, conclui-se que não é necessário sua aplicação para obter o enraizamento desse porta-enxerto.

\section{Referências}

ANDRADE, E. R.; DAL BÓ, M. A.; SCHUCK, E. Avaliação da resistência de germoplasma de videira ao Fusarium oxysporum f.sp. herbemontis. Revista Brasileira de Fruticultura, Cruz das Almas, v. 16, n. 1, p. 139-145, 1994.

BACKES, M. A Composto de lixo urbano como substrato para plantas ornamentais. 1990. Dissertação (Mestrado em Agronomia) - Departamento de Horticultura e Silvicultura. Faculdade de Agronomia. Universidade Federal do Rio Grande do Sul, Porto Alegre.

BELLÉ, S. Uso da turfa "Lagoa dos Patos" (Viamão/ RS) como substrato hortícola. 1990. Dissertação (Mestrado em Fitotecnia) - Departamento de Horticultura e Silvicultura. Faculdade de Agronomia. Universidade Federal do Rio Grande do Sul, Porto Alegre.

BIASI, L. A.; POMMER, C. V.; PINO, P. A. G. S. Propagação de porta-enxertos de videira mediante estaquia semilenhosa. Bragantia, Campinas, v. 56, n. 2, p. 367-376, 1997.

BIASI, L. A.; BOSZCZOWSKI, B. Propagação por estacas semilenhosas de Vitis rotundifolia cvs. Magnolia e Topsail. Revista brasileira de Agrociência, Pelotas, v. 11, n. 4, p. 405-407, 2005. 
BOTELHO, R. V.; MAIA, A. J.; PIRES, E. J. P.; TERRA, M. M.; SCHUCK, E. Efeitos de reguladores vegetais na propagação vegetativa do porta-enxerto de videira '4343' (Vitis vinifera $x$ V. rotundifolia). Revista Brasileira de Fruticultura, Jaboticabal, v. 27, n. 1, p. 6-8, 2005.

FACHINELlO, J. C.; HOFFMANN, A.; COSTA, J. N.; KERSTEN, E.; FORTES, G. R. L. Propagação de plantas frutiferas de clima temperado. Pelotas: UFPEL, 1995. $178 \mathrm{p}$.

FERREIRA, L.; KERSTEN, E.; FACHINELLO, J. C. Época de coleta, ácido indolbutírico e triptofano no enraizamento de estacas de pessegueiro. Scientia Agricola, Piracicaba, v. 59, n. 2, p. 327-333, 2002.

GONÇALVES, A. L.; MINAMI, K. Efeito de substrato artificial no enraizamento de estacas de calanchoe (kalanchoe x blossfeldiana cv. SINGAPUR, Crassulaceae). Revista da Sociedade da Agricultura, Piracicaba, v. 51, n. 2, p. 240-244, 1994.

HARTMANN, J. L. M.; KESTER, D. E.; DAVIES JUNIOR, F. T.; GENEVE, R. L. Plant propagation: principles and practices. Uppe0r Saddle Rwir: Prentice Hall, 1997. 770 p.

JARVIS, B. C. Endogenous control of adventitious rooting in non-woody cuttings. In: JACKSON, M. B. (Ed.). New root formation in plants and cutting. Dordrecht: Matinus Nijhoff, 1986. p. 191-222.

LEONEL, S.; RODRIGUES, J. D. Efeito da época de estaquia, fitorreguladores e ácido bórico no enraizamento de estacas de portaenxertos de videira. Scientia Agricola, Piracicaba, v. 50, n. 1, p. 27-32, 1993.

MACHADO, M. P.; MAYER, J. L. S.; RITTER, M.; BIASI, L. A. Ácido indolbutírico no enraizamento de estacas semilenhosas do porta-enxerto de videira 'VR043-43' (Vitis vinifera x Vitis rotundifolia). Revista Brasileira de Fruticultura, Jaboticabal, v. 27, n. 3, p. 476-479, 2005.
PIRES, E. J. P.; BIASI, L. A. Propagação da videira. In: POMMER, C. V. Uva: tecnologia da produção, poscolheita e mercado. Porto Alegre: Cinco Continentes, 2003. p. 295-350.

RAMOS, J.D.; MATOS, L.E. S.; GONTIJO, T. C.A.;PIO, R.; JUNQUEIRA, K. P.; SANTOS, F. C. Enraizamento de estacas herbáceas de 'Mirabolano' (Prunus cerasifera Ehrn) em diferentes substratos e concentrações de ácido indolbutírico. Revista Brasileira de Fruticultura, Jaboticabal, v. 25, n. 1, p. 189-191, 2003.

ROBERTO, S. R.; PEREIRA, F. M.; NEVES, C. S. V. J.; JUBILEU, B. S.; AZEVEDO, M. C. B. Enraizamento de estacas herbáceas dos porta-enxertos de videira Campinas (IAC 766) e Jales (IAC 572) em diferentes substratos. Ciência Rural, Santa Maria, v. 34, n. 5, p. 1633-1636, 2004.

ROBERTO, S. R; PAIOLO, P. A. C. Avaliação de técnicas para a multiplicação de estacas semilenhosas de aceroleira 'Dominga' (Malpighia emarginata D.C.). Semina: Ciências Agrárias, Londrina, v. 23, n. 2, p. $165-$ 172, 2002.

SCHUCK, E. Porta-enxertos para a videira. In: ENCONTRO NACIONAL SOBRE FRUTICULTURA DE CLIMA TEMPERADO, 6., 2003, Fraiburgo. Anais... Fraiburgo: Parque da Maçã, 2003. p.185.

SILVA, A. L.; FACHINELLO, J. C.; MACHADO, A. A. Efeito do ácido indolbutírico na enxertia e enraizamento da videira. Pesquisa Agropecuária Brasileira, Brasília, v. 21, n. 8, p. 865-871, 1986.

SOUSA, J. S. I. Uvas para o Brasil. Piracicaba: FEALQ, 1996. $791 \mathrm{p}$.

ZIETEMANN, C.; ROBERTO, R. F. Efeito de diferentes substratos e épocas de coleta no enraizamento de estacas herbáceas de goiabeira, cvs. Paluma e Século XXI. Revista Brasileira de Fruticultura, Jaboticabal, v. 29, n. 1, p. 31-36, 2007. 